Our research indicates that, in general, outward mobility schemes do produce positive benefits at multiple levels: individual, institutional, and national. The experiences of the countries we studied also show that careful upfront analysis is needed to make smart decisions regarding goals and outcomes, important precursors to a program's form and function, and that effective administration, to include attention to return and reentry issues, is central to a program's ultimate success. In short, a complex set of factors, unique to each country, must be considered in developing a program that is successful in meeting its intended goals.

\section{Graduate Student Learning Abroad: Emerging Trend?}

\section{John M. Dirkx, Kristin Janka Millar, Brett Berquist, AND Gina VizVARY}

John M. Dirkx is professor, Department of Educational Administration, College of Education, Michigan State University, East Lansing. E-mail: dirkx@msu.edu. Kristin Janka Millar, director of international engagement, Honors College, Michigan State University. E-mail: kristin@ msu.edu. Brett Berquist, executive director, Office of Study Abroad, Michigan State University. E-mail: berquis6@msu.edu. Gina Vizvary is a research assistant, Department of Educational Administration, Michigan State University. E-mail: vizvaryg@msu.edu.

\begin{abstract}
$\Delta$ dvances in technology, the growing diversity of our $\mathrm{A}_{\text {population, and the influences of globalization are }}$ precipitating dramatic changes in the policy and practice of higher education and graduate study, in particular. In the past few years there has been a steady increase in the number of graduate students engaged in studying abroad and of programs and disciplines offering these opportunities. Increasingly, higher education institutions see study abroad as an important means of internationalization. In the United States, many professional schools and graduate programs are creating international experiences that range from short-term, faculty-led programs, independent study, and research, to joint and dual degree programs. In other countries, postgraduate study abroad places more emphasis on individual approaches. Despite this increased activity, we know very little about the nature of these experiences and student learning outcomes.
\end{abstract}

\section{Differences in Graduate and Undergraduate Study ABROAD}

While similar in some respects to undergraduate study abroad, graduate level study abroad should represent a fundamentally different experience. As adult learners, graduate students often bring years of professional work and life experience to their graduate study, and tend to be more mature than undergraduate students. The average age of a graduate student in the United States is 34 years, at least Io years older than the typical undergraduate student. Graduate programs are typically more specialized and focused on professional disciplines - such as education, law, medicine, business, or social work. These differences have important implications for the design, facilitation, and assessment of international experiences for graduate students. So what is graduate study abroad like?

\section{New Research on Graduate Study Abroad}

A new project-the Graduate Learning Experiences and Outcomes study, led by Michigan State University-focuses on understanding the landscape of international learning opportunities offered at the graduate level. This past year an online survey was administered to I5 US research institutions in the Midwest and New York University, providing information on I72 faculty-led group experiences for graduate students. Study findings indicate that graduate and professional students participate in a diverse set of experiences, across an array of academic disciplines. Programs include a mix of students with different levels of educational preparation, with about half being restricted to students at the graduate level. These programs also tend to be less than four weeks in length and made up of 6 to 20 students. Very few programs have a foreign-language requirement for participation. Most programs are offered for academic credit and receive support from their institution's study-abroad office. By and large, students are expected to contribute some or all of the program costs; and while financial support by an organization in the host country is very rare, most programs do partner with organizations in the host country, such as health clinics and hospitals, universities, businesses, and local nonprofits.

Students participating in these programs go to 59 different countries, but, by far, China is the most frequent destination followed by France, Brazil, Germany, Italy, England, Argentina, South Africa, Japan, Ghana, and India. While in country, students stay in local hotels or other tourist accommodations, such as bed and breakfasts. They participate in a wide variety of activities, including lectures and presentations and a range of experiential activities-including community engagement, academic field trips, cultural field trips, research, service, volunteer work, group discussions, and guided observations, often augmented with "alone time" and reflective activities at the group or individual level. Faculty reported they lead programs so they can collaborate with other faculty abroad, help students prepare 
for international careers, create a global presence for the university, develop global partnerships, increase the number of students going abroad, and help students challenge their perceptions. Their choice of country reflects their passion for a particular region or country.

\section{Trends And Trade-OffS}

Graduate-level study abroad is becoming increasingly common and an important means of internationalizing higher education. As evident from the Graduate Learning Experiences and Outcomes study, in the United States, study abroad at the graduate level tends to be small groups of graduate students led by faculty for no more than three or four weeks. The short length of time in the host country shapes the types of opportunities that are possible. When programs are structured so that the group always travels together and stays in hotels or tourist lodging, the opportunity to challenge one's perspective may be limited. While this arrangement may limit immersion by participants in the host culture, it does provide a $24 / 7$ "within group" experience that may be very powerful personally and professionally for the participating graduate students. The potential for deep learning is magnified when participants in these groups represent different disciplines and nationalities.

\section{In the United States, many profes- sional schools and graduate programs are creating international experiences that range from short-term, faculty-led programs, independent study, and re- search, to joint and dual degree pro- grams.}

\section{Future Research}

But what makes study abroad a graduate-level experience? Why should graduate programs bother with creating and implementing such experiences for their students? While professional development and global learning seem laudable outcomes for these programs, they alone do not seem to set graduate study abroad apart from undergraduate study abroad. Given the numbers of programs and students becoming involved, we need to know more about what distinguishes these activities as graduate level experiences. Research is needed to understand how these experiences contribute to graduate-level preparation, and how academic content and the disciplines might influence learning out- comes associated with these experiences. We need to know more about how growing numbers of international students participating in these programs are influencing the nature of the learning derived by all students. Finally, we need to know more about individual (versus group) experiences and international graduate study, comparatively, around the world. The individual research approach is prominent in many educational systems and we may gain valuable knowledge through learning how other countries structure such postgraduate work.

\section{CONCLUSION}

Graduate study-abroad experiences should compliment and deepen the learning that occurs within a student's graduate program. But what are the indicators of such experiences? How might we know if graduate study-abroad programs are truly achieving such outcomes or whether they are simply extensions of faculty-led short-term study-abroad programs at the undergraduate level? Given the dramatic changes on the horizon for graduate education, how might programs use international experiences to address the needs arising from these changes? Our work raises more questions than it provides answers, but hopefully these findings will provide the basis for an engaging exploration of the aims and scope of study abroad at the graduate level.

\section{Introduction: Historical Perspective on Contempo- rary Issues}

Adam Nelson, Coordinator

Adam Nelson is professor of Educational Policy and History at the University of Wisconsin-Madison. E-mail: anelson@education.wisc.edu.

"In the spring of 20I3, the Worldwide Universities Network (WUN) commissioned a report to help university leaders think about the future of higher education. The network asked: what would the landscape of international higher education look like a generation from now? What challenges and opportunities lay ahead for universities, especially "global" research universities? In response, I convened a group of prominent historians from around the world to consider how universities in the past responded to major historical change. Specifically, I asked each to write a brief essay-identifying a "key moment" in the internationalization of higher education: a moment, when universities 